\title{
Effect of intravenous propranolol on QT interval
}

Sir,

We read with interest the study of Milne et al. (Br Heart $\mathcal{F} 1980$; 43: 1-6) dealing with a new method to assess the effects of intravenous propranolol on QT interval and wish to comment on some aspects of their paper.

(1) The QT interval of the electrocardiogram can be interpreted only after correction for the cardiac cycle length. Bazett's formula is frequently used for this purpose and expressed as the symbol QTc: an absolute value of QTc exceeding $\mathbf{4} 40 \mathrm{~ms}$ means prolongation. ${ }^{1}$ Previous reports indicate that a prolonged QTc may represent a significant risk index for major cardiac arrhythmias in acute or healed myocardial infarction. ${ }^{23}$ On the other hand, antisympathetic drugs are used in such clinical situations and may help prevent sudden death. ${ }^{45}$ Propranolol, ${ }^{6}$ alprenolol, ${ }^{7}$ and bretylium tosylate ${ }^{8}$ shorten the QTc interval and this may be how they reduce the incidence of major arrhythmias.

The conclusions drawn by Milne et al. do not apparently support this view.

(2) It is surprising however that such a relevant point is not supported by an unbiased statistical analysis. ${ }^{9}$ Furthermore, when comparing (variance analysis) the QTc of all 15 patients with measurements obtained in sinus rhythm and during atrial pacing, before and after propranolol $(0.1 \mathrm{mg} / \mathrm{kg}$ over three minutes) it is evident (see Table) that: (a) propranolol induces a marginally significant $(p<0.065)$ reduction of QTc when infused in patients in sinus rhythm; (b) the lengthening of QTc after propranolol during atrial pacing is statistically not significant; (c) there is a highly

Table $Q T c$ before and after propranolol (mean $\pm S D$ ) in 15 patients

$$
Q T c=\frac{Q T}{\sqrt{R R}}(m s)
$$

\begin{tabular}{|c|c|c|}
\hline & $\begin{array}{ll}\text { Sinus rhythm } \\
\text { Before } \quad \text { After } \\
416 \pm 18 & 401 \pm 23\end{array}$ & $\begin{array}{ll}\text { Atrially paced } & \\
\text { Before } & \text { After } \\
485 \pm 39 & 498 \pm 40\end{array}$ \\
\hline$F=35 p<0.00001$ & $\times \times \times-\times \times \times$ & $-\times \times \times-\times \times \times$ \\
\hline$F=3.67 p<0.065$ & $\times \times \times-\times \times \times$ & \\
\hline$F=0.81 \quad N S$ & & $\times \times \times-\times \times \times$ \\
\hline$F=38 p<0.00001$ & $\times \times \times$ & $-\times \times \times$ \\
\hline$F=65 p<0.00001$ & $\times \times \times$ & $-\times \times \times$ \\
\hline
\end{tabular}

significant $(p<0.00001)$ lengthening induced by the proposed new method, irrespective of whether the drug was given.

(3) While the method described by Milne et al. deserves to be validated in a larger and more homogeneous series, it does not seem that the suggested action of propranolol in prolonging the QT interval duration during atrial pacing is substantiated.

\author{
Paolo E Puddü, \\ Remy Jouve, \\ Jean Torresani, \\ C.H.U. Marseille Nord, \\ Hôpital Nord Service de Cardiologie, \\ Chemin des Bourrely, \\ 13326 Marseille Cedex 3, \\ France.
}

\section{References}

1 Moss AJ, Schwartz, PJ. Sudden death and the idiopathic long Q-T syndrome. Am f Med 1979; 66: 6-7.

2 Ahnve S, Lundman T, Shoaleh-Var M. The relationship between QT interval and ventricular arrhythmias in acute myocardial infarction. Acta Med Scand 1978; 204: 17-9.

3 Schwartz PJ, Wolf S. QT interval prolongation as predictor of sudden death in patients with myocardial infarction. Circulation 1978; 57: 1074-7.

4 Wilhelmsson C, Vedin JA, Wilhelmsen L, Tibblin G, Werkö L. Reduction of sudden deaths after myocardial infarction by treatment with alprenolol. Preliminary results. Lancet 1974; ii: 1157-60.

5 Multicentre International Study. Improvement in prognosis of myocardial infarction by long-term beta-adrenoreceptor blockade using practolol. $\mathrm{Br} \mathrm{Med}$ f 1975; iii: 735-40.

6 Stern S, Eisenberg S. The effect of propranolol (Inderal) on the electrocardiogram of normal subjects. Am Heart f 1969; 77: 192-5.

7 Nyberg G, Vedin A, Wilhelmsson C. QT time in patients treated with alprenolol or placebo after myocardial infarction. Br Heart $\mathcal{f}$ 1979; 41: 452-5.

8 Singer PA, Crampton RS, Bass NH. Familial Q-T prolongation syndrome. Convulsive seizure and paroxysmal ventricular fibrillation. Arch Neurol 1974; 31: 64-6.

9 Glantz SA, Biostatistics: how to detect, correct and prevent errors in the medical literature. Circulation $1980 ; 61$ : $1-7$. 
This letter was shown to Dr Milne and his colleagues who reply as follows:

\section{Sir,}

Puddu and his colleagues point out many of the difficulties in the interpretation of the QT interval, and of the changes of the QT interval occasioned by atrial pacing and by physiological or pharmacological manoeuvres. Though physiological changes in the QT interval can possibly be corrected for concomitant rate changes by the use of correction factors such as Bazett's formula, there is no evidence that changes of rate induced by atrial pacing or by drugs can be similarly corrected. Indeed the results of our research suggest that in the case of atrial pacing, in which rates were used which extended beyond the physiological range assessed by Bazett, simple hyperbolic correction was completely inaccurate as implied in paragraph $2 c$ of the letter by Puddu and his colleagues.

In order to compensate for the bradycardia induced by propranolol, a comparison of pre- and post-propranolol QT intervals can be made by correcting both values for rate according to Bazett's formula. Alternatively, rate can be controlled by atrial pacing at identical frequencies both before and after drug administration. Our results indicated that, when using Bazett's correction the QTc usually shortened after propranolol, but when fixing the rate by atrial pacing, the QT tended to lengthen. As is pointed out by Puddu and colleagues, this result was not statistically significant.

These combined results suggest that one or other method is inappropriate and we are, as yet, pre- pared to accept that making comparisons at nonphysiological atrial paced rates may lead to incorrect results. We are also very unsure, however, about the validity of assuming that Bazett's correction can be applied to pharmacologically induced changes of rate. Rickards et al. ${ }^{1}$ confirm our belief that simple hyperbolic correction should be not applied to QT interval changes induced by atrial pacing. Their results, like ours, lead to the conclusion that Bazett's correction would seriously overestimate the QTc at atrial driven rates above 100 a minute.

We should also point out that the results of our work do not necessarily apply to the effects of rate changes or beta-blockade on the QT interval in abnormal repolarisation syndromes. The QT interval response to the imposition of an artificial rate, abnormal depolarisation sequence, or pharmacological intervention may be characteristically different from the results in our "normal" series.

$$
\begin{aligned}
& \text { J Milne, } \\
& \text { A J Camm, } \\
& \text { D E Ward, } \\
& \text { R A J Spurrell, } \\
& \text { Department of Cardiology, } \\
& \text { St Bartholomew's Hospital, London. }
\end{aligned}
$$

\section{Reference}

1 Rickards AF, Akhras F, Baron DW. Effects of heart rate on QT interval. In: Meere C, ed. Proceedings of VIth world symposium on cardiac pacing. Montreal: Laplante and Langevin, 1979. 2:7. 